\title{
A New Theory Producing Heterosis of Crops
}

\author{
Peizhan Tian \\ Centre of Germplasm Introduction and Crop Breeding of Jilin Province, Changchun, China \\ Email: peizhantian@163.com
}

How to cite this paper: Tian, P.Z. (2021) A New Theory Producing Heterosis of Crops. Open Access Library Journal, 8: e7837. https://doi.org/10.4236/oalib.1107837

Received: August 5, 2021

Accepted: September 7, 2021

Published: September 10, 2021

Copyright (C) 2021 by author(s) and Open Access Library Inc.

This work is licensed under the Creative Commons Attribution International License (CC BY 4.0).

http://creativecommons.org/licenses/by/4.0/

\begin{abstract}
In this paper, the theory of heterosis controlled by core traits (genes) was put forward. Growth period traits and stem type traits were two core traits of heterosis in crops. However, due to the low yield of early-maturing parents, although the relative advantage was high, the absolute yield level of heterosis in the F1 generation was not necessarily high. Because seed production requires that the difference between two parents' growth periods should not be very big, it also limited the potential of using gene interaction of growth periods to improve heterosis. In addition, the genes that control the growth period also included the genes that control each growth stage, so that the genes that control the growth period were not many, but not very few, because there were more genes that disperse and weaken the action intensity of major genes and increasing heterosis of the $\mathrm{F}_{1}$ generation was difficult. The genes controlling different stem types were all single. When the maturity of two parents is the same or similar, the combinations with different stem types got the maximum heterosis of grain yield, and the $\mathrm{F}_{1}$ absolute yield level is also the highest. Therefore, in heterosis utilization breeding, the differences of stem types should be mainly used and differences of growth periods should be properly used. Mechanism and root producing heterosis of crops were that strong interaction of major genes among different types of the most important quality traits (ecological traits) lead to great improvement in the vitality of all quantitative traits. Growing period and Stem type were two nucleus traits producing heterosis of crops. Therefore this theory was called as core trait theory producing heterosis of crops.
\end{abstract}

\section{Subject Areas}

Agricultural Science

\section{Keywords}

Crop, Heterosis, Theory 


\section{Introduction}

Further Studying and determining the mechanism and root producing heterosis of crops had great importance not only for genetics theory studying, but also simplifying crossbreed breeding programs and increasing breeding efficiency.

\section{Main Hypothesis Concerning Heterosis of Crops}

On the basis of relationship between inherit and developing in science research, there were four hypotheses that were accepted by great majority of researcher.

\subsection{Dominance Hypothesis}

Davenpor (1908) firstly put forward a concept of dominance hypothesis. He said" crossbreed vigour was result of affects and each other affects among beneficial genes. Shull (1911), Hayes and Eest (1912) published dominance hypothesis. They considered that crossbreed vigour came from heterozygosis and the hypothesis aroused recognizing that "harmful genes were covered by dominance genes".

\subsection{Super-Dominance Hypothesis}

Shull (1908) On the basis of heterozygosis of a gene having more vigour than its homozygosis, due to increasing diversity of gametes to be combined produced physiological stimulation to developing. The hypothesis recognized that heterosis came from different quality combination of double parents to give rise to each other effects of isogenic line, growth and developing and adaptability of heterozygote were better more than that of homozygote, relativily between heterosis size and heterozygous degree was close. East and Hayes (1912) supported these points and recognized that super-dominance was controlled by one gene and expressing in several charecters [1].

\subsection{Epistasis Effect Hypothesis}

The more and more researches proved that epistasis effects had important affect in forming heterosis. Sibin, et al. (1997) using 150 locus that overcastted whole genome in race researched genetics of forming F1 heterosis, and found that each other affects among non-alleles were generally exited in population to be study, and thought that epistasis effects were important genetics basis forming heterosis.

\subsection{Study on Heterosis Groups and Models}

Beal (1880) using crosses controlling fertilization for maize varieties showed that their yields were increased $10 \%$ to $50 \%$ than that of double parents of opening fertilization. Allard (1960) introduced and used cross test of maze variety of Hayes and Olsen in 1919 and found that most increasing yield were Horse tooth type $\times$ Silty type and Horse tooth type $\times$ Hard grain type, so crosses of different 
source parents produced more heterosis than that of close source parents [2].

\section{Direction Further Studying Heterosis Theory}

On basis above mention and observation and studies in crop breeding, several key points of producing heterosis should be raised: 1) Two parents must be genetically homozygous; 2) One or several quality characters have a decisive role informing heterosis, it is likely to be related to nucleus organ traits, or the most important traits of plants; 3 ) Strong interaction between genes of this or several most important quality traits had a significant effect on the performance of other quantitative traits, so that each quantitative trait could all show obvious heterosis; 4) Through the research, it was only necessary to clarify which character or characters were the nucleus characters that play a decisive role, Combined with the growth and development law of the F1 generation, it is possible to clarify the root of heterosis.

It could be seen from the above that the research on crop heterosis in the world has long been divorced from the road of "trait gene-heterosis". Instead, it turned to the differences in genotype and blood relationship. For example, in the early days, it was considered that the hard-grained type $\times$ horse tooth type (maize inbred line) was a high heterosis combination, but it was later denied by facts. Now the heterosis is attributed to the hybridization between different "germplasm groups", in essence, it still focuses on genotype or fuzzy blood relationship. The expansion of the research scope and its uncertainty had also led to greater blindness in practice.

\section{Net System of Genetic Character of Yield Performance of Crop Helping Finding the Nucleus Traits of Heterosis}

Net system of genetic character of yield performance of crops included basic contradiction of yield performance of crops, Ecology of crop variety, and Yield ability science (included plant type science) of crop variety, three parts.

After more than 30 years of research, this theoretical system not only successfully reveals and answers the long-standing problem of how crop yield is formed It also divided all the characters of plants into two different characters: ecological characters and yield ability characters through the analysis of the composition of the basic contradiction of crop yield. These characters are also genetically different traits with obvious differences. From breeding, it will naturally differentiate into the breeding of non-additive effect of quality traits and the breeding of additive effect of quantitative traits. This makes it clear that the breeding of heterosis was actually the breeding of non-additive effect on quality traits. The breeding of inbred lines or inbred crop varieties was the breeding of additive effect on quantitative characters. Ecological traits were a group of traits controlled by quality traits and had great influence on the performance of quantitative traits [3] [4], and could naturally become the nucleus traits of heterosis (Figure 1). 


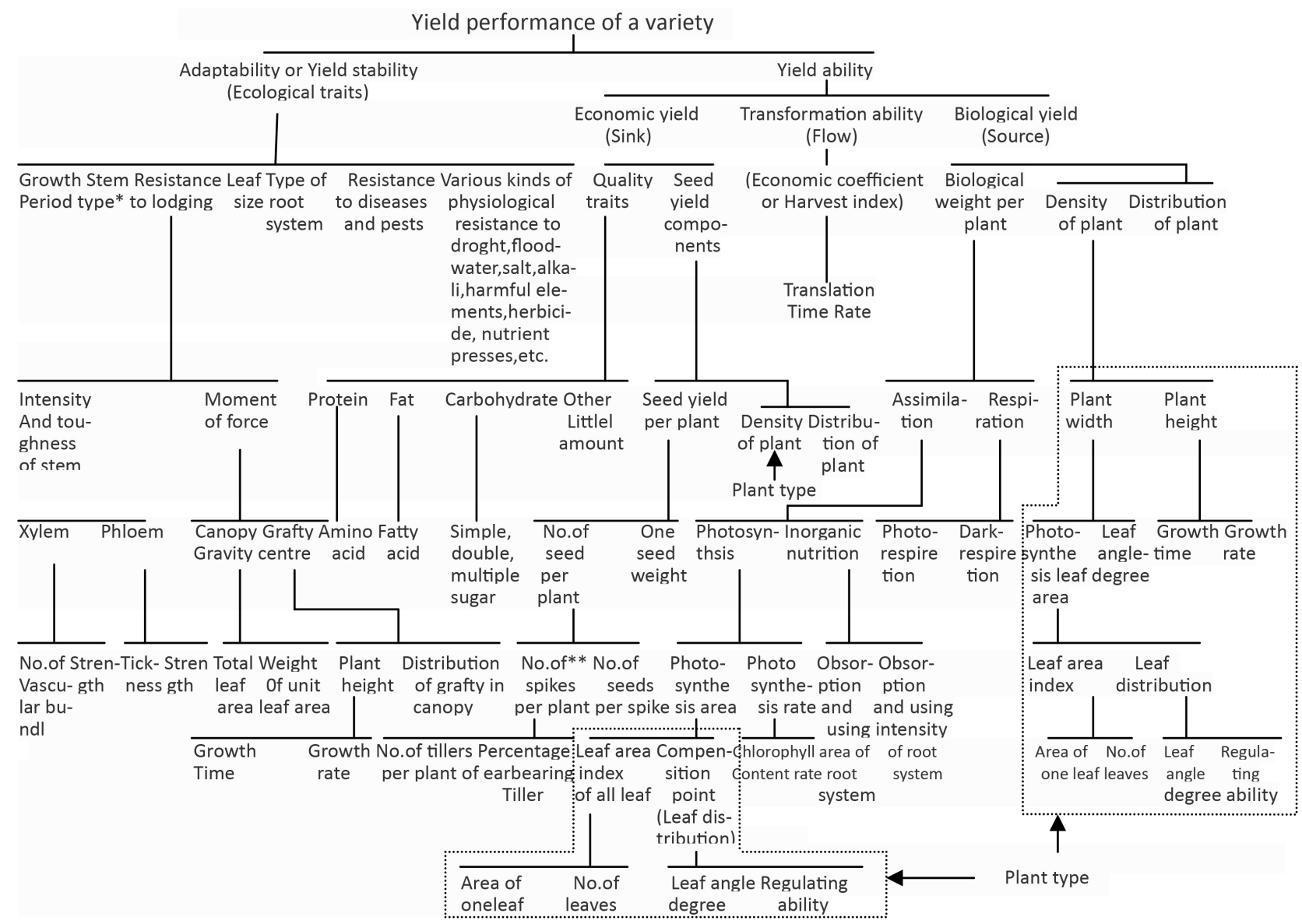

Figure 1. Net system of basic contradiction of variety performance and character composition of corn and grass family crops. ${ }^{\star}$ The stem type was pod-bearing habit in soybean; ${ }^{\star \star}$ There were petiole (and its length) and nodule, No. of pod per plant, No. of seed per pod in soybean.

\section{Root of Producing Crop Heterosis: Nucleus Characters Playing a Decisive Role}

Figure 1 showed that the important ecological characters included growth period, pod-bearing habit (or stem type), lodging resistance, leaf size, root type, disease resistance, insect resistance, and various physiological resistances (cold, heat, drought, waterlogging, salt, alkali, harmful ions, nutrient stress, herbicides, etc.). Among them, the growth period and stem type had influences in the greatest intensity and the widest range on others.

\subsection{First Nucleus Character of Heterosis: Growing Period}

Growth period traits were formed under the long-term action of two specific ecological factors, namely light and temperature. Light and temperature both come from the sun, which is a powerful ecological condition that is not easy to be artificially changed. This determined the strength of the growth period traits formed under their direct action and its comprehensive and strong influence on other quantitative traits. People can only adapt to this ecological character, and can't change it at will. According to the specific light and temperature condi- 
tions, we can cultivate varieties that can't mature early or late [5].

Once the early-maturing or late-maturing varieties with great changes in growth period are planted, not only other ecological characters were changed, and but also all quantitative characters were changed obviously [6]. For example, the plant height of early-maturing varieties became short, the vegetative body became thinner, the lodging resistance became stronger, the leaf area of the population became smaller, and the photosynthetic intensity of leaves increased. Late-maturing varieties grew tall and luxuriant, showed weak lodging resistance, increased disease resistance in leaves, and even fail to mature normally. All the traits related to grain yield became very poor. Another example is that the northern cultivars moved to the south. Due to the shortening of the growth period, the soybean varieties with indeterminate pod-bearing habits showed some characteristics of semi-determinate type, and the number of pods at the top of the main stem increased. On the contrary, Gemsoy, an extremely early-maturing soybean variety in Northern Europe was planted in Hainan Island, but its growth period was delayed, and instead, it changed from determinate type to indeterminate type. All these phenomena have confirmed that growth period genes can exert great influence on all other trait genes (including other ecological trait genes and all quantitative trait genes) and determine their performance. Therefore, it should be a core trait that determines the size of heterosis. The difference between the two parents' growth periods will directly affect the grain yield heterosis of the F1 generation. Table 1 shows that the greater the difference between two parents' growth days, the greater the heterosis index of average grain weight per plant. This is the direct evidence that the difference of growth period characters between two parents determines the heterosis of $\mathrm{F} 1$ grain yield.

\subsection{Second Nucleus Character of Heterosis: Main Stem Type}

The second core trait that decided the heterosis of crops was the stem type trait, but different crops paid very different attention to this research. For example, the pod-bearing habits of soybean varieties are very different, which can easily attract the attention of soybean breeders [7]. It had been determined early that it is a very important ecological trait. However, up to now, the breeders of Gramineae crops have not put forward and found the research results of the differences in ecological characters of stems among varieties (such as the obvious differences in stem types of corn varieties) and their importance.

Table 1. Relationship between parents growing period difference and F1 seed yield heterosis in soybeans.

\begin{tabular}{ccccccc}
\hline $\begin{array}{c}\text { Difference of growth } \\
\text { period of parents } \\
\text { (days) }\end{array}$ & \multicolumn{3}{c}{ No. of crosses combination of different heterosis } & \multicolumn{2}{c}{$\begin{array}{c}\text { Total No. of } \\
\text { combination }\end{array}$} & $\begin{array}{c}\text { Average heterosis } \\
\text { index (\%) }\end{array}$ \\
\hline $0-5$ & $19(17.1)^{*}$ & $56(50.5)$ & $27(24.3)$ & $9(8.1)$ & 111 & 115.77 \\
$6-15$ & $2(3.6)$ & $20(36.4)$ & $22(40.0)$ & $11(20.0)$ & 55 & 125.90 \\
$>15$ & $3(12.0)$ & $10(40.0)$ & $4(16.0)$ & $8(32.0)$ & 25 & 133.75 \\
\hline
\end{tabular}

${ }^{*}$ Number in brackets was percentage of crosses. 
The reason why the stem type character was called the core character is that its different types could cause changes in other ecological characters and all quantitative characters. The change of ecological types of stems of all crops is mainly manifested in the difference between the top and bottom of stems. Type having thin top and bigger stem diameter difference was infinite, the small difference between top and base was finite, and the middle type was sub-finite. Since all vegetative organs and reproductive organs were derived from stems, the Internode thickness of the main stem directly determines the performance of quantitative traits such as petiole length, leaf size of different levels of plants, distribution of vegetative mass, length of tidbits, number of seeds, and grain yield. Especially, when you see varieties with different stem types, you will feel that they are obviously different in plant shape (Figures 2-6), and the characters that make up the plant shape are also quantitative characters. In addition, stem type traits also affect the performance of ecological traits such as lodging resistance to a certain extent, so it should be the second core trait to decided heterosis.

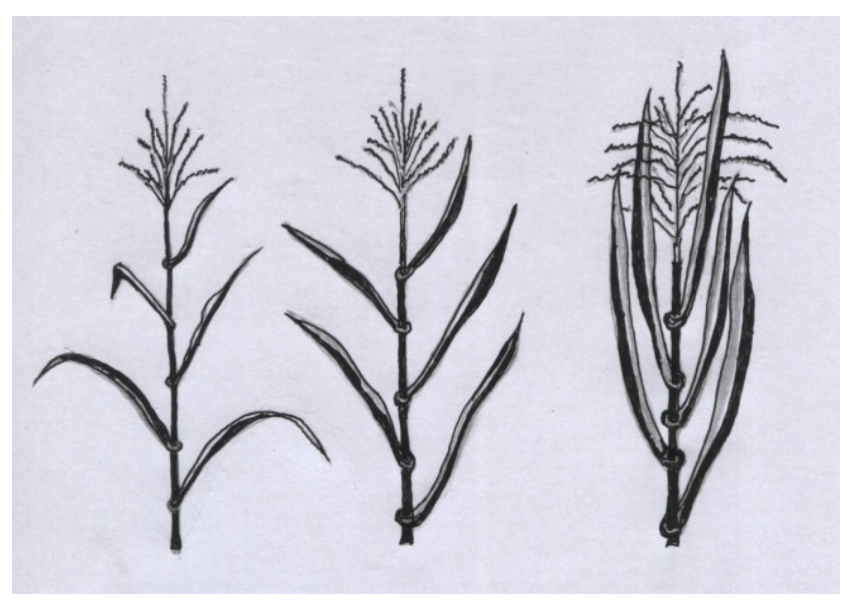

Figure 2. Signal of Stem type of different corn varieties, from left to right: indeterminate, semi-determinate, determinate type.

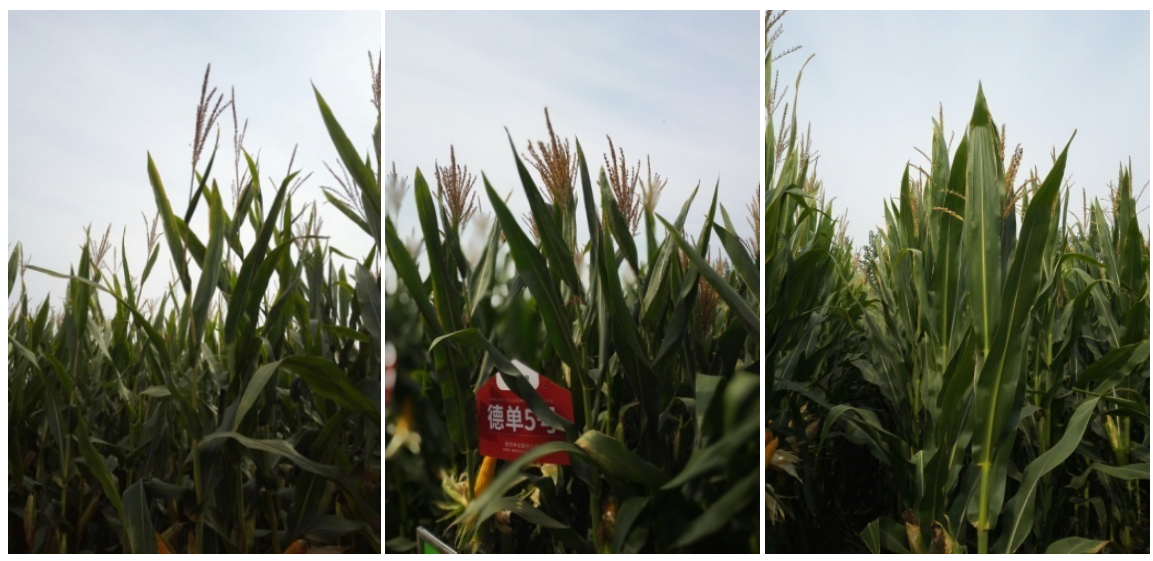

Figure 3. Typical example of different stem type corn hybrid in Henan Province, China (2018). From left to right: indeterminate (Yufeng 98), semi-determinate (Dedan 5), determinate (Yuhe 588) type. 

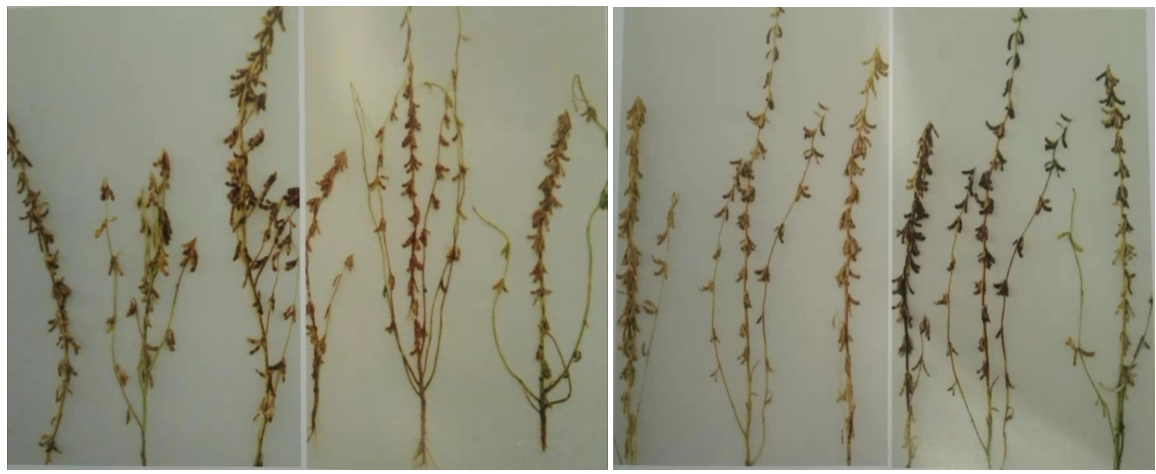

Figure 4. Heterosis difference of crosses using different stem type parents in soybeans (including four crosses). In each cross, from left to right, female, male, F1 plants ranged in proper order. The leftmost figure was cross between soybean variety using big difference stem type produced F1 super equity heterosis, and F1 plant having both female and male some features, but growing periods of parents were the same. Others three figures were all crosses of less difference in stem type, could not produced super equity heterosis.

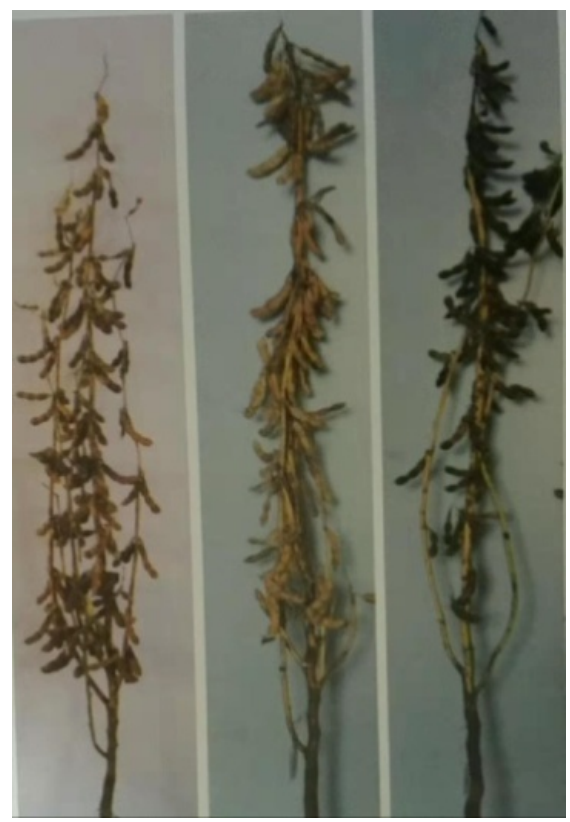

Figure 5. Influence of Pod-bearing habit trait (stem type) in soybean to distribution of seed yield. From left to right: Jilin No. 3 (indeterminate), Jilin 20 (semi-determinate), Gongjiao 7514-2 (determinate). Seed yield distribution were respectively: below and low-middle more, above less; in general well-distributed; above more and below less

According to the research of soybean, the pod-bearing habit was formed under the long-term action of precipitation and its distribution in growth period, and the precipitation and its distribution given by nature were also difficult for human beings to change in a long period of time. Generally speaking, area of precipitation being more than $600 \mathrm{~mm}$, which was suitable for planting determinate stem type varieties; less than $500 \mathrm{~mm}$ is suitable for inderminate varieties; between 500 and $600 \mathrm{~mm}$, it was suitable for semi-determinate varieties [8]. According to the investigation, there were similar differences in the stems of 


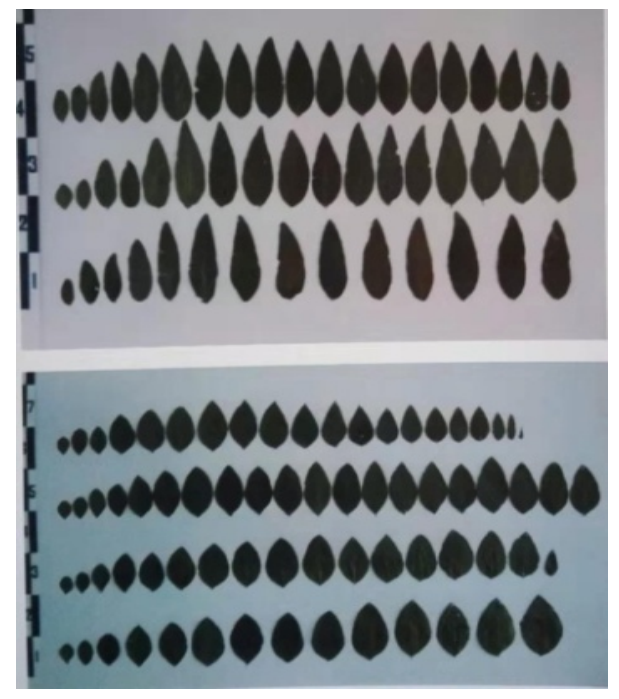

Figure 6. Influences of different stem type on leaf size at different nod-place. Above part was needle shaped leaf variety, from above to below: middle mature and indeterminate variety Jiunong No. 21, middle and semi-determinate variety Jilin No.20, middle and determinate variety Tongnong 2188; below part round shaped, from above to below: Hardin (middle and indeterminate) Jilin No. 21. Jilin No25, middle mature, semi-determinate; Gongjiao 7514-2, middle mature, and determinate. A comparison with Figure 5 showed each other corresponding relationship between distribution of seed Yield and leaf size at different pod-place.

corn hybrids. For example, many varieties such as Xianyu 335 were typical infinite stems, Zhengdan 958 and Yuhe 588 were typical finite stems, and Jingke 968 and Jingke 728 were sub-finite stem type (Figure 2 and Figure 3 ).

If the precipitation and its distribution were unchanged, the original stem type should be kept, and the stem type should not be changed greatly. The failure of Professor R. L. Cooper, American soybean breeder, to extend his limited dwarf soybean varieties in Heilongjiang Province of China was a profound lesson.

The precipitation in American Corn Belt was not much and scattered during the growth period, which was the adaptation area of typical infinite stem corn and soybean varieties. Most of China's corn planting areas were sub-limited and infinite stem planting areas. In plain areas, only Dandong in the east of Liaoning Province and Southern Henan Province had precipitation exceeding $600 \mathrm{~mm}$, and limited stem type corn and soybean had good adaptability. The breeders there can gain great advantages in breeding limited stem inbred lines and varieties because they can get more abundant limited stem resources. Practice has proved that only when the stem types of the two parents were quite different, and the limited type must be involved, the F1 generation can produce two kinds of genes to interact and form a super equal advantage, which showed some characteristics of both the female parent and the male parent (Figure 4), thus obtaining a high advantage combination. The maximum heterosis of soybean appears in this combination, and it was more ideal that the highest heterosis can be obtained even under the same or similar growth period of two parents (Table 2) [8] [9]. 
Table 2. Influence of growing period and stem type on F1 heterosis in soybeans.

\begin{tabular}{|c|c|c|c|c|c|c|c|}
\hline \multicolumn{3}{|c|}{ Female } & \multicolumn{3}{|c|}{ Male } & \multirow{2}{*}{$\begin{array}{c}\text { F1 leaf area } \\
\text { index heterosis } \\
(\%)\end{array}$} & \multirow{2}{*}{$\begin{array}{l}\text { F1 seed yield } \\
\text { heterosis (\%) }\end{array}$} \\
\hline Variety & $\begin{array}{c}\text { Growing } \\
\text { period }\end{array}$ & $\begin{array}{c}\text { Main stem } \\
\text { type }^{\star}\end{array}$ & Variety & $\begin{array}{c}\text { Growing } \\
\text { period }\end{array}$ & $\begin{array}{c}\text { Main stem } \\
\text { type }\end{array}$ & & \\
\hline Dongnong 72-806 & Early & Semi & Changxis-17 & Middle-late & In & 130.5 & 179.6 \\
\hline Jilin No. 15 & Middle-early & Semi & Changxis-17 & Middle-late & In & 136.2 & 175.4 \\
\hline Jilin No. 17 & Middle-late & Semi- & Corsoy & Middle-late & In & 112.9 & 149.4 \\
\hline
\end{tabular}

${ }^{*}$ In: indeterminate type, semi: semi-determinate type, De: Determinate type.

Besides growth period and stem type, no third similar trait can be found.

In order to reveal the essence of stem type traits, author selected four pairs of allelic line in soybean, both of which were semi-determinate, but the difference in top thickness was only $2 \mathrm{~mm}$, and conducted a six-year experiment. The results showed that the average yield of the main stem with big difference in top and bottom thickness was higher, and the variation index between years was lower, which indicated that it was more suitable for planting in this area. In two dry years and two normal years in six years, the yield of variety that had a big difference was higher. However, in 2005, when there was much rain and less sunshine during the growth period, and in 2008, when the rainfall was as high as $852 \mathrm{~mm}$, the difference was small and the yield was higher, which indicated that it was more suitable for rainy conditions. These show that the more essential difference between pod-setting habits and stem types was the difference in thickness between the upper and lower ends of the main stem [10].

Nucleus character theory of heterosis of crops in soybeans was confirmed. Different ecology type of stems in maize hybrid was also found. Passing further research success could be obtained. We believed that effects and results of same type genes in different crops should be same or similar.

Inference process, from "most important ecology (quality) trait was produced under most important ecology condition", to "producing strong each other effect between different type genes of most important ecology trait", to "the each other effects lead to great improvement in vitality of all of quantitative traits and producing stronger heterosis" was accord with logic.

\section{Conflicts of Interest}

The author declares no conflicts of interest.

\section{References}

[1] Shull, G.H. (1908) The Composition of a Field of Maize. Journal of Heredity, 4, 296-301. https://doi.org/10.1093/jhered/os-4.1.296

[2] Allard, R.W. (1960) Principles of Plant Breeding. John Wiley \& Sons, New York, 485.

[3] Tian, P. (2014) Theoretical Genetics and Breeding Science of Crop. Science and Technique Publishing House of Jilin, Changchun.

[4] Tian, P. (2015) Basic Principle and Technique System of Crop Breeding. Open 
Access Library Journal, 2. https://doi.org/10.4236/oalib.1102032

[5] Tian, P. (1979) Problem on Growing Period in Soybean Breeding. Acta Agronomica Sinica, 5, 57-62.

[6] Tian, P. (1979) Changing Regularity of Main Character of Soybean Variety Planting in South and North in China and Its Applying. Agricultural Science in China, 1, 56-61.

[7] Tian, P. (1975) Problem on Pod-Bearing Habit in Soybean. Acta Genetica Sinica, 2, 337-343.

[8] Tiian, P. (2018) Ecology of Crop Variety. Teaching Materials.

[9] Tian, P. (2018) The Science of Yielding Ability of Crops. Teaching Materials.

[10] Tian, P. (2013) Difference Diameter at Top and Base of Main Stem Was Essentially Distinguishing Factor of Different Pod-Bearing Habit in Soybean, Jilin Agricultural Science, 38, 4-6, 10. 